\title{
Visual observing by rhesus monkeys: Some relationships with social dominance rank
}

\author{
RICHARD H. HAUDE, JOHN G. GRABER, and ALBERT G. FARRES \\ University of Akron, Akron, Ohio 44325
}

\begin{abstract}
Five rhesus monkeys were tested in a visual exploration situation to determine whether the mean frequency or mean duration of visual observing were systematically related to the dominance status of the observing animal. A dominance hierarchy among the five subjects was first determined by means of a competitive food-getting task. Following dominance testing, visual exploration testing was begun. All subjects were permitted to observe all other subjects in a round-robin pairing system involving two animals at a time. In each pairing, one animal served as the experimental subject (observer); the other as the stimulus (visual incentive). A highly significant linear effect of dominance was found in regard to duration of observing. Subjects high in the dominance hierarchy observed for significantly shorter durations than low-dominant subjects. Significant effects of dominance on the frequency of observing were also found, with animals intermediate in the hierarchy viewing more frequently than animals at either extreme. The data were interpreted in terms of the arousal and reduction of fear as a function of dominance and also through the notion of dominance distance.
\end{abstract}

Studies of visual observing behavior (visual exploration; visual exploratory behavior) in monkeys have consistently shown that monkeys prefer to view social visual incentives such as other live monkeys or photographic representations of them compared with other nonsocial visual incentives (Butler, 1954, 1958, 1961; Butler \& Woolpy, 1963; Haude, Kruper, \& Patton, 1966; Symmes, 1959). The consistency with which such findings are reported underscores the fact that, among primates, visual observing is perhaps the most effective means of acquiring information about conspecifics, i.e., other members of the same species as the observer.

More recently, studies of visual observing in monkeys have been directed toward analyzing the functional aspects of visual exploration with particular regard to social processes. The emotional or affective arousal value of a variety of socially relevant stimuli has been investigated in several studies. Sackett $(1965,1966)$ has reported that visual exploration by rhesus monkeys of color slides depicting various categorres of socialcommunicative behavior by other monkeys is clearly influenced by the rearing conditions of the experimental subjects or observers. On the basis of these studies, Sackett has suggested that certain categories of socialcommunicative stimuli such as slides depicting infant monkeys and slides depicting threat behavior possess "prepotent general activating properties" for infant rhesus monkeys.

Redican, Kellicutt, and Mitchell (1971) have employed a similar technique in studying the preferences of juvenile female monkeys for viewing various categories of social-communicative behavior. These authors report that their juvenile animals appeared to distinguish

This report is based partially on an MA thesis submitted to the University of Akron by John G. Graber. Requests for reprints should be addressed to Richard $H$. Haude, Department of Psychology. University of Akron, Akron, Ohio 44325. between facial expressions only among slides of peers, and not of infants or adults.

The studies cited above suggest that the investigation of visual observing behavior may prove useful in analyzing social-communicative processes in monkeys. However, efforts to extend and to integrate investigations of visual exploration seem likely to be hampered somewhat by the lack of some systematic framework within which to interpret the various findings. This report is directed toward the development of a limited account of some relationships between visual observing by rhesus monkeys and the threat- or fear-arousing potential of social-communicative stimuli within the context of social dominance and dominance-distance.

The choice of social dominance as a possible correlate of visual observing is based upon considerations such as the fact that dominance relationships encompass a wide variety of socially relevant behavior involving threat and submission. Also, relatively strict linear dominance hierarchies have been observed in both feral and lab. reared monkeys (Maier \& Maier, 1970). It should be noted that concern over such issues as linearity, unidimensional vs. multidimensional attributes, and measures of dominance has been expressed from several quarters (Baenninger, 1968; Bernstein, 1964; Boelkins, 1967; Rowell, 1966). Nevertheless, there appear to be reasonably reliable tests for dominance, and obtained dominance relationships show good long-term stability (Bernstein, 1969; Biernoff, Leary, \& Littman, 1964; Miller \& Murphy, 1956).

\section{METHOD}

Subjects

Subjects were five male rhesus monkeys (Macaca mulatta), all approximately 3 years of age. All subjects had been used in one prior study involving leverpressing for food reward. None had undergone previous dominance or visual exploration testing. 
Table 1

Total Number of Food Objects Taken from All Other Monkeys During 10-Day Dominance Test

\begin{tabular}{|c|c|c|c|c|c|}
\hline & \multicolumn{5}{|c|}{ Monkeys } \\
\hline & $\mathrm{B}$ & $\mathrm{D}$ & C & $A$ & E \\
\hline I ood Objects & 292 & 264 & 231 & 154 & 59 \\
\hline
\end{tabular}

Note-Maximum posstble $=400$

One subject $(\mathrm{C})$ suffered partial leg paralysis and was unable to engage in visual observing as measured in this study. He was, however, quite capable of competing in the food object tests, and consequently was used only as a stimulus monkey in the visual exploration portion of the study. All subjects were housed individually so that each monkey could see every other monkey. Direct physical contact between subjects was limited to the dominance testing situation only.

\section{Apparatus}

Dominance testing was carried out in a standard Wisconsin General Test Apparatus (WGTA) composed of two chambers $(100 \times 64 \times 64 \mathrm{~cm}$ each) separated by a barrier of vertical steel bars. One chamber was designated as the animal chamber, and was illuminated from above through an opaque Plexiglas ceiling and ventilated by an exhaust fan. The other chamber was desigrated as the experimental chamber, in which a movable stimulus tray could approach the barrier separating the two chambers, allowing subject(s) in the animal chamber to reach through the barrier and gain access to the stimulus tray.

Visual observing behavior was measured in a test chamber $(71 \times 56 \times 48 \mathrm{~cm})$ with a translucent Plexiglas celling, above which were a light $(71 / 2 \mathrm{~W})$ and a speaker for white noise. Within the chamber, a small vertical shaft $(11 \times 13 \mathrm{~cm})$, open at the bottom. was constructed. One wall of this shaft, which also constituted the front wall of the chamber itself, contained a small window $(2.5 \mathrm{~cm}$ high $\times 10.0 \mathrm{~cm}$ wide). Two parallel beams of infrared light ( $87 \mathrm{c}$ Wratten filters) passed across the shaft parallel with the window and activated two photocell relays connected in series. In order for a monkey to observe the environment exterior to the chamber, it had to place its head up into the shaft from below, thus interrupting the beams of light, which in turn activated an impulse counter and a runninglime meter. Measures of the frequency and duration of visual exploration were thus obtained.

\section{Procedure}

Dominance testing. A competitive food-getting test was used 10 determine the dominance hierarchy of the subjects. Each animal was paired in the animal chamber of the WGTA with every other monkey in a counterbalanced round-robin fashion. The sequence of pairings was $\mathrm{AB}, \mathrm{DC}, \mathrm{BE}, \mathrm{AC}, \mathrm{DE}, \mathrm{BC}, \mathrm{DA}$, $\mathrm{CE}, \mathrm{BD}, \mathrm{AE}$. A stimulus tray, in the center of which was placed a raisin or sucrose tablet, was presented to the pair of monkeys by the experimenter. For each pair of monkeys, the member who put the food object into its mouth was recorded. Ten food-competition trials per pair of anmals per day were presented. Dominance testing continued for 10 consecutive days, one round-robin per day, yielding 10 test sessions per pair of animals. The dominance measure was based upon the total number of food objects obtained over the 10-day test period.

Visual observing. Following the determunation of the dominance hierarchy, the test of visual observing began. The visual exploration chamber was placed adjacent to and contiguous with the experimental chamber of the WGTA. The window in the visual exploration chamber was placed so that an observer animal could look out the window, through the experimental chamber of the WGTA, and into the animal chamber of the WGTA. On Days 1 and 2 of visual observing, the subjects were placed in the visual exploration chamber with the window completely covered on the outside with electrical insulation tape. On Days 3-12. the tape was removed and the subjects were allowed to view the lighted, but empty, animal chamber of the WGTA. On Days 13-28, each monkey was placed either in the visual exploration chamber (as an observer) or in the animal chamber of the WGTA (as a stimulus animal). The sequence of pairngs was (first letter represents observer; second letter represents stimulus animal): Day $13-\mathrm{AB}, \mathrm{ED}, \mathrm{BA}, \mathrm{DE}$; Day 14 $\mathrm{AC}, \mathrm{EB}, \mathrm{DC}, \mathrm{AE}$; Day 15-DB, EC, AD. BE; Day 16-DA, BC, $\mathrm{EA}, \mathrm{BD}$. This sequence was repeated three times (Days 17-28). (Note: Animal C was used only as a stimulus animal.) This round-robin was counterbalanced such that no monkey was placed in either the exploration chamber or the WGTA twice in a row on any day. Nor did any round-robin sequence occur twice in a row. Four pairings occurred each day for a 16-day period, yielding four complete round-robins (each monkey observed every other monkey four times). The frequency and cumulative duration of observing were recorded for each $30-\mathrm{min}$ test session.

\section{RESULTS}

Based on the total number of food objects taken during the 10-day dominance test period a dominance hierarchy (from high to low) of B-D-C-A-E emerged. A chi-square test indicated that the differences in total number of food objects were significant $\left(\chi^{2}=177.60\right.$; $\mathrm{df}=4 ; \mathrm{p}<.001)$. Table 1 presents the dominance data.

A summary of the mean frequencies and mean durations of visual observing for each pair of observer and stimulus monkeys is shown in Table 2.

The frequencies and cumulative viewing times were analyzed by means of an analysis of variance for repeated measurements of the same subjects. Subjects were treated as blocks and trials as treatments. Significant differences between subjects for mean response frequency per session and mean duration of observing per ses-

Table 2

Mean Durations (Minutes) and Mean Frequencies Per Session of Visual Exploration for Each Pair of Test and Stimulus Monkeys

\begin{tabular}{|c|c|c|c|c|c|c|c|c|c|c|c|c|}
\hline \multirow{3}{*}{$\begin{array}{c}\text { Test } \\
\text { Monkeys }\end{array}$} & \multicolumn{12}{|c|}{ Stimulus Monkeys } \\
\hline & \multicolumn{2}{|c|}{$\mathrm{B}$} & \multicolumn{2}{|c|}{$\mathrm{D}$} & \multicolumn{2}{|c|}{$\mathrm{C}$} & \multicolumn{2}{|c|}{$\mathbf{A}$} & \multicolumn{2}{|c|}{ E } & \multicolumn{2}{|c|}{ Overall Mean } \\
\hline & $\Gamma^{*}$ & $\mathrm{D}^{* *}$ & $\mathrm{~F}$ & $\mathrm{D}$ & $\mathbf{F}$ & $\mathrm{D}$ & $F$ & $\mathrm{D}$ & $\mathbf{F}$ & $\mathrm{D}$ & $\mathrm{F}$ & D \\
\hline B & & & 44.3 & 8.3 & 57.8 & 8.3 & 49.0 & 6.4 & 48.8 & 7.0 & 50.0 & 7.5 \\
\hline $\mathrm{D}$ & 108.8 & 11.8 & & & 100.3 & 6.6 & 88.8 & 7.2 & 83.5 & 14.3 & 95.4 & 10.0 \\
\hline A & 63.3 & 11.3 & 58.8 & 14.4 & 61.0 & 14.2 & & & 65.3 & 16.3 & 62.1 & 14.1 \\
\hline $\mathrm{E}$ & 20.8 & 23.3 & 30.0 & 18.9 & 43.5 & 21.3 & 34.5 & 23.9 & & & 32.2 & 21.9 \\
\hline
\end{tabular}


sion were found $(F=47.84, \mathrm{df}=3,45, \mathrm{p}<.01$, and $\mathrm{F}=46.73, \mathrm{df}=3,45, \mathrm{p}<.01$, respectively). A posteriori comparisons between individual means for each subject were performed using Tukey's HSD test (Kirk, 1968). Except for the comparison between Subjects A and B, each subject's mean response frequency was significantly different from all other subjects' mean response frequencies $(p<.05)$. Among mean cumulative viewing times, only the comparison between Subjects B and D was nonsignificant.

The data were also analyzed to determine whether differential incentive value or stimulus value existed among the subjects when used as the stimulus animal. An analysis of variance for repeated measures using subjects as blocks showed no significant differences for either measure. Table 3 presents the mean response frequency and mean cumulative viewing time per session for each subject when being used as the visual stimulus object.

Finally, the ranked differences (differences between adjacent dominance positions) were examined for the entire dominance hierarchy. In the obtained hierarchy B-D-C-A-E, a one-way ranked difference of 1 would be indicated by the pairs $\mathrm{BD}, \mathrm{DC}, \mathrm{CA}, \mathrm{AE}$; a one-way ranked difference of 3 by pairs $B A, D E$, etc. A two-way ranked difference of 1 would be indicated by pairs BD, DB, DC, CD; a two-way ranked difference of 3 by pairs $\mathrm{BA}, \mathrm{AB}, \mathrm{DE}, \mathrm{ED}$, etc. The mean frequency and mean duration of visual exploration per session for both one-way and two-way ranked differences are shown in Table 4.

An analysis of variance for repeated measures using ranks as treatments indicated no significant differences in either response frequency or duration of visual exploration among the two methods of determuning ranked differences.

\section{DISCUSSION}

These data indicate that visual observation by rhesus monkeys of other rhesus monkeys within the same dominance hierarchy is significantly related to the dominance status of the observer monkey. More specif. ically, the higher the dominance status of the observer the less cumulative time is spent in viewing other animals. The effect on the frequency of viewing is less clear-cut but appears to indicate that animals occupying intermediate positions in the hierarchy observe more frequently than animals at the high and low extremes

Table 3

Mean Response Frequency and Mean Duration (Minutes) Per Session of Visual Exploration When Serving as Stimulus Object

\begin{tabular}{lccccc} 
& \multicolumn{5}{c}{ Stimulus Monkey } \\
Measure & B & D & C & A & E \\
\hline Mean response frequency & 64.3 & 44.3 & 66.3 & 57.4 & 65.8 \\
Mean duration of viewing (min) & 15.5 & 14.9 & 12.6 & 12.5 & 12.6 \\
\hline
\end{tabular}

Table 4

Mean Response Frequency and Mean Duration of Visual Exploration Per Session for One-Way and Two-Way Ranked Differences in Dominance

\begin{tabular}{|c|c|c|c|c|}
\hline & 1 & $\begin{array}{c}\text { Ranked D } \\
2\end{array}$ & $\begin{array}{c}\text { ifferences } \\
3\end{array}$ & 4 \\
\hline & \multicolumn{4}{|c|}{ One-Way Ranking } \\
\hline Mean frequency & 70.0 & 73.3 & 66.3 & 48.8 \\
\hline \multirow[t]{2}{*}{ Mean duration (min) } & 10.4 & 7.8 & 10.4 & 7.0 \\
\hline & \multicolumn{4}{|c|}{ Two-Way Ranking } \\
\hline Mean frequency & 69.0 & 62.3 & 56.5 & 34.8 \\
\hline Mean duration (min) & 13.5 & 12.8 & 12.7 & 15.1 \\
\hline
\end{tabular}

in the hierarchy.

A possible explanation for these findings may involve the concept of dominance-distance and the role of fear or anxiety in visual observing behavior. The concept of dominance-distance implies that in linear dominance hierarchies, as found in this study, there will be a systematic change in the interaction among members as the distance between their respective dominance positions changes. Plotnik, King, and Roberts (1965) have reported a greater frequency of interaction between monkeys with close (small) dominance-distance as compared with monkeys with greater dominance-distance.

The motivational basis or dynamics underlying visual observation among organisms of various species has been the focus of considerable attention. Symmes (1959) has suggested that in nonhuman primates visual exploration of potentially hostile environments may serve to reduce anxiety. Butler (1964) has supported Symmes' notion that monkeys will actively observe a fear-arousing visual stimulus. In an observational study of attention structure among rhesus macaques, Virgo and Waterhouse (1969) have reported that under seminatural conditions subordinate animals within a group systematically direct their visual attention toward their superiors until the dominant animal becomes the major focus of attention. However, Virgo and Waterhouse also point out that dominance can be established either on the basis of essentially positive relationships with other group members, e.g., soliciting grooming, or on the basis of fear through aggressive encounters.

In the context of the present study it seems likely that a dominance relationship based on fear or aggression was operating, as opposed to one established on some positive basis. This is because the dominance testing involved a priority of access technique, and also because the subjects were not part of a cohesive group. If this were the case, then, as dominance rank decreases, fear or anxiety would presumably increase in relation to the number of potentially threatening animals of superior dominance status. Following Symmes (1959), visual observing behavior would then increase in relation to subsequent anxiety or fear reduction. Virgo and Waterhouse (1969) have also suggested that subordinate animals watch the actions of their 
immediate superiors in order to avoid conflict. The mean cumulative viewing time measures of the present study clearly support these predictions.

It should be noted that another possible prediction from the Symmes and the Virgo and Waterhouse notions was not supported by the cumulative viewing time measures. High-ranking animals were not observed for significantly longer cumulative times than lower ranking animals. This suggests that, at least in the present study, it was the dominance rank of the observer animal which chiefly determined mean cumulative viewing time.

The fact that animals ranking high in dominance look at others for shorter durations might also function in the determination of sucial space (Chance, 1967). This concept implies that the distances between individuals will be adjusted on the basis of a combination of the positive and negative influences which exist between them. Visual observing is seen as a mechanism by which a subordinate animal can maintain a safe distance from a superior. The idea of social space may be related to the dominance-distance idea of Plotnik, King, and Roberts (1965). The more closely adjacent are the positions of two individuals within a dominance hierarchy, the more frequently they will tend to interact with each other. In this study the mean frequency of observing measures seems to follow such a pattern. Those animals holding intermediate positions in the hierarchy (Ranks 2 and 4), and thus more closely adjacent in rank to all other subjects, showed more frequent observing behavior than animals on the extremes (Ranks 1 and 5). Note again that the anımal holding Rank 3 served as a stimulus animal only. Although not significant, the mean frequency of observing by ranked differences showed an identical pattern.

In conclusion, this study clearly demonstrates that dominance status is systematically related to visual observing by rhesus monkeys. Moreover, these data obtained under conditions rather widely different from observational studies in natural settings show reasonably good agreement with previously reported findings. It may be that the various aspects of the dominance concept, and the different measures of it, are not so fundamentally different as has been assumed. Or it may be that the role of fear, fear reduction, and dominancedistance may serve as a basis for the development of a theoretical account powerful enough to encompass a variety of dominance-related phenomena.

\section{REFERENCES}

Baenninger, L. P. Dominance hierarchies: The problem of unidimensionality. American Zoologist, $1968,8,698-699$,

Bernstein, I. S. Role of the dominant male rhesus monkey in response to external challenges to the group. Journal of Comparative and Physıological Psychology, 1964, 57. 406.

Bernstein, I. S. Stabulity of the status hierarchy in a pigtail monkey group (Macaca nesestrina). Animal Behavior, 1969. $17,452-458$.

Biernoff, A., Leary, R. W., \& Littman, R. A. Dominance behavior of paired primates in two settings. Journal of Abnormal and Social Psychology, 1964, 68, 109-113.

Boelkins, R. C. Determination of dominance hierarchies in monkeys. Psychonomic Science, 1967, 7, 317-318.

Butler, R. A. Incentive conditions which influence visual exploration. Journal of Experimental Psychology, 1954, 48, 19-23.

Butler, R. A. The differential effect of vsual and auditory incentives on the performance of monkeys. Americal Journal of Psychology, 1958, 71,591-593.

Butler, R. A. The reactions of rhesus monkeys to motion pictures. Journal of Genetic Psychology, I961, 98, 239-245.

Butler, R. A. The reactions of rhesus monkeys to fear-provoking stimuli. Journal of Genetic Psychology, 1964, 104, 321-330.

Butler, R. A., \& Woolpy, J. H. Visual attention in the rhesus monkey. Journal of Comparative and Physiological Psychology, 1963, 56, 324-328.

Chance, $M$. R. A. Attention structure as the basis of primate rank orders. Man, 1967, 2, 503-518.

Haude, R. H., Kruper, D. C., \& Patton, R. A. Relationships among measures of visual explorations in monkeys. Journal of Comparative and Physiological Psychology, 1966,62, 156-159.

Kirk, R. E. Experimental design. Procedures for the behavioral sciences. Belmont: Brooks/Cole, 1968. pp. 88-90.

Maier, R. A., \& Maier, B. M. Comparative animal behavior. Belmont: Brooks/Cole, 1970, pp. 220-225.

Miller, R. E., \& Murphy, J. V. Social interactions of rhesus monkeys: I. Food-getting dominance as a dependent variable. Journal of Social Psychology, 1956, 44, 249-255.

Plotnik, R. J., King, R. A.. \& Roberts, L. An objective analysis of social dominance in the squirrel monkey. Proceedings of the American Psychologycal Assiciation, 1965, 1, 109-110.

Redican, W. K., Kellicutt, M. H., \& Mitchell, G. Preferences for facial expressions in juvenile rhesus monkeys (Macaca mulatta). Developmental Psychology, $1971,5,539$.

Rowell, T. E. Hierarchy in the organization of a captive baboon group. Animal Behavior, 1966, 14, 430-443.

Sackett, G. P. Responses of rhesus monkeys to social stimulation presented by means of colored slides. Perceptual and Motor Skills, $1965,20,1027-1028$.

Sackett, G. P. Monkeys reared in isolation with pictures as visual input: Evidence for an innate releasing mechanism. Sclence, 1966, 154, 1468, 1471-1473.

Symmes, D. Anxiety reduction and novelty as goals of visual exploration by monkeys. Journal of Genetic Psychology, $1959,94,181-198$.

Virgo, H. B., \& Waterhouse, M. J. The emergence of attention structure amongst rhesus monkeys. Man, $1969,4,85-93$.

(Received for publication August 11,1975 , revision accepted October 10,1975 ) 